Wiesław Babik*

\title{
Sustainable Development of Information Society: Towards an Ethics of Information
}

The paper is a continuation of my previous two papers concerning the same subject-matter: the problems of the global information society. The first paper discussed the ecology of information [2], while the second one concentrated on society's access to information and knowledge [3]. Also the present paper is related to those issues because we are all builders of the information society, and one of the essential elements of the process is our multi-lateral co-operation in the areas of new technology transfers, and innovation. Information ethics is one of the main components of the information and knowledge society. Among various issues relating to the development of the information society, in addition to information and knowledge management, information ecology, ethics is found behind all the activities involving information, its generation, transformation, perception, and availability.

In recent years, we have observed in many areas an increase of interest in ethics applied to resolve practical problems. The development and spreading of information and communication technologies generates the need of ethical analysis of the condition of the society relying on information and knowledge, called the information society. There is a demand for codification of the principles that determine the rules of information activities in the global information infrastructure. And that is the field of information ethics named infoethics, too.

In this paper, I will present the origin of that field, recent directions of research and ethical implications in the development of modern information and communication technologies in the global information society.

\section{The Information Market}

Any kind of co-operation among people and organisations is always based on the flow of information in one or two directions. The quantity and quality of information are constantly growing.

\footnotetext{
* Jagiellonian University, Institute of Information and Library Science, Krakow, Poland
} 
New technologies create unlimited possibilities for the generation, processing, storage, retrieval, and perception of information. When we co-operate with each other, we become participants in the information market, because co-operation is often based on the exchange and delivery of applicable information. That process is important because information and innovation are specific goods, even commodities in the market. Wherever you deal with a commodity, money is present as well. And that creates the problems related to a proper selection of information and its management. Here, information ethics intervenes between the process participants.

\section{Responsibility for Information}

The development of the information society does not concern only the development of information resources or information potential, but also shaping of an awareness of responsibility for what we do with information in this case, or the awareness of information ethics. Responsibility for information exists regardless of the fact whether information is published or delivered in a traditional manner or through the Internet. In case of Internet publication and information transfer, there is a greater freedom of operation and a lower credibility of the information content. Undoubtedly, responsibility for information is borne by the author or generator, being often the source of the information. But there are also cases when the author/source is unknown or pretending to be somebody else. In both real world and the Internet, there is abundance of various types of cheaters and fraudsters. The problem of responsibility, in the Internet in particular, is related to the availability of documents which are protected by law in the real world (e.g. by copyrights).

It seems that a discussion of responsibility for information, or of information credibility is not sufficiently present in traditional and electronic media yet. We are still at the stage of relishing information, without paying attention to information credibility. It is necessary to disseminate an attitude of responsibility for content published on the Internet.

\section{Information Ethics}

\subsection{The Origin}

Those who were the first to use the term of information ethics were Robert Hauptman, the founder of the "Journal of Information Ethics", and Rafael Capurro in his 1988 article on "Informationethos und Informationethik". Since 1997, UNESCO has been organising INFOethics Congresses dedicated to ethical, legal, and social challenges of cyberspace enrich international reflection on the im- 
portance of ethical and societal aspects of the Information Society. Both UNESCO and the International Telecommunication Union have contributed to international meetings dedicated to the information society since 2003 (WSIS meetings) [9]. Specific issues of global information ethics are discussed there, including general access to information, equality of access to information and knowledge, confidentiality of information, network security and respect for such universal values as truth, justice, solidarity, tolerance, human dignity, or responsibility.

The term global information ethics is used more and more often in scholarly literature. That term is treated as being supreme with respect to the ethics represented by professionals working in the areas of information, computer science, cybernetics, networks or machines, as well as to ethics applied to the issues connected with information transfer or information technology.

\subsection{Directions of Studies}

Information ethics studies the attitudes and application of ethical standards in the broadly understood areas of information, information technologies, and information activities.

The following directions are identified in information ethics:

- descriptive ethics dealing with the analysis and clarification of ethics in specific times and circles;

- normative ethics dealing with the determination of the principles and standards of ethical conduct;

- applied ethics understood as the field involved in the application of ethical standards in specific situations.

"Journal of Information Ethics" enumerates the following fields of interest [10]:

- ethical aspects of the development of information and communication technologies;

- influence of information technologies on individuals, organisations, and social reality;

- issues relating to the expansion of access to information;

- data security, privacy, intellectual property, copyrights, computer crime.

According to those differentiations, information ethics is a comprehensive discipline which connects descriptive ethics with normative and applied ethics. As a descriptive theory, the field is the area of study of the influence of the power structure on the information attitude and tradition in various cultures and times, e.g. the influence on the development of ethical values related to information transfer and processing in the global information society, ethical conflicts connected with the use of new information technologies, and making information 
available. As a normative theory, ethics determines the standards of professional conduct and behaviour in the global information infrastructure. Rafael Capurro stated that a basis of ethical thinking in the information field is the Universal Declaration of Human Rights [4], and especially those provisions of the Declaration which concern respect for human dignity, confidentiality of information, equal chances, privacy, right to free expression etc.

Ethical issues appear in all fields of information activities. Global information ethics is a discipline which is understood broadly, and it covers the ethics of information professionals, the ethics of information users, and the issues of privacy.

\subsection{Object and Tasks}

Information ethics concerns human activity related to information, or our relationship with respect to information, or what we do with information, how we generate, process, and distribute it in the form of new technologies and innovations, which contain a lot of processed information. Information ethics concerns all stages of information and communication processes.

At each stage, intended information distortion or manipulation may occur, e.g. lying, fabrication, or keeping the sources of information secret (of course, outside the sphere of state or corporate secrets). One may not introduce false information to the information market in a democratic society. Those who generate such information bear personal responsibility (or even liability).

T. Froehlich mentioned four groups of ethical problems concerning information [5]:

- responsibility for the assurance of the general access to information as a basic human right;

- ethical aspects of information production;

- ethical aspects of information gathering and organisation;

- ethical aspects of making information available.

For that reason, information ethics may be considered within the information society in the following areas:

- ethical aspects of information gaining, processing, and making available;

- professional ethics of information workers;

- ethics of information developers and users.

Information ethics is part of general ethics. Truth is essential in the transfer of information. "Only in the atmosphere of truth may people safely and creatively subject the world to themselves: only by living in truth may people act maintaining own dignity in all areas of activity. Lies exert a destructive influence on the moral authenticity of human existence, creating a contradiction between internal conviction and 
external expression. That deforms interpersonal communication and, consequently, threatens with the destruction of the society" [8]. Information ethics points out to the specialists dealing with information transfer of information the possibilities of passing information to the largest possible number of receivers, as well as the social acceptance of the role of information in the communication process. Information ethics points out liability for information, its objectivity, and reliability because those features of information allow for information collection and transfer. Liability for truth lies with the individuals who work in the sphere of information.

The tasks of information ethics:

- shaping a reflective attitude towards information, its nature and moral obligations concerning information generation and reception in various life situations;

- recognition of basic values and ranking those values in the processes of information reception, transmission, and selection;

- assumption of responsibility for ourselves and others and for our moral choices when implementing information processes;

- identification of essential moral problems in the global information society and of the methods to resolve such problems;

- showing the significance of ethical principles for personal and social development, the shaping of proper relationships between people in social, economic, and political life;

- development of the skills of presentation of one's position in dialogue with others, and of democratic joint decision-making.

The implementation of those tasks should lead to the following:

- correct selection of values and value ranking in personal and social life;

- successful resolution of ethical doubts and problems in accordance with the assumed hierarchy of values and common good;

- application of the principles of harmonious co-existence and collaboration in individual, local, and global information environments.

\section{Threats and Opportunities of Information Ethics}

The development of a global information society is a natural consequence of the development and expansion of modern information and communication technologies, especially of the Internet. In a society in which everything is almost at a stretch of our hand through global networks, many threats and challenges appear, including ethical challenges. An information society is characterised by a common awareness of the role of information in social and individual life, guarantees of free access to information, joint development of professional and reliable information, proper knowledge resources, and making them available to all who need them. 
A basic threat to the information society is social exclusion, which may be understood differently, being in contradiction to the concept of a society in which all have equal chances of building knowledge, access to knowledge, and its processing and sharing, taking into account one's individual needs.

\section{The Implementation of Information Ethics}

\subsection{Ethical Problems of Information Collection and Production}

The ethical problems concerning information gathering are related to censorship and selection. Censorship means the purposeful exclusion of information from circulation based on decisions which are justified by religious, political, moral or other reasons. Information selection is related to the choice of information in accordance with the objectives of a given organisation. Selection procedures may comply with the interests of a particular social group. In both cases of censorship and information selection, ethical balance is lost. The fundamental ethical problem concerns the determination of the boundaries of intellectual freedom.

Ethical problems are also associated with information production, and, in particular, with intellectual property and copyright protection. Presently, there is contradiction between property right protection on the part of authors and publishers on the one hand and the so-called active right to information, or the postulate of universal access to information on the other hand. On the ground of such issues, we notice such dilemmas as whether information should be treated as property, or what is morally and ethically more important: the idea of knowledge sharing, creation, and availability, or rather the idea of the individual author's property protection.

\subsection{Ethical Culture of Persons Dealing with Information}

The skill of making proper ethical choices is an element of ethical culture ${ }^{1}$ which is manifested by the following:

- possession of appropriate knowledge on ethics and ethical deeds;

- awareness of the role and significance of choices related to information;

- respect for other people's views and opinions;

- ability to select proper means of information gathering, processing, and making available;

- reliability and honesty in the selection of information sources.

1 Culture has various definitions. One of them is based on the anthropological interpretation of that term and it says: Culture is a relatively integrated wholeness of human conduct running in accordance with common patterns which are developed and assumed by a social community during their collaboration, including the products of such conduct [6]. 
Ethical culture may be analogously interpreted as knowledge, customs and skills corresponding to information treated as a component of the reality which surrounds man, and as a factor which affects the conduct and achievements of both individuals and societies. In particular, the expressions of culture are the following:

- knowledge of the essence of ethics and its functions;

- high level of awareness of ethics and its significance;

- knowledge and skills of correct use of the terms and concepts related to morality;

- skill of correct interpretation of conduct;

- respect for somebody else's views;

- skill and reliability of the selection of the sources of information and the methods of information gathering, processing and making available.

\subsection{Brokering of Information}

The profession of information broker or infobroker puts a strong emphasis on information ethics as a response to 21st century requirements [7]. The role of information brokers is to disseminate professional information and ethical principles of conduct in information handling. A number of infobroker ethical codes have been developed. They contain the rules of conduct and professional activity. Infobroker operations are not limited to the implementation of orders and observation of contracts with customers, but they also require respect for the law and professional codes of practice. Presently, infobroker circles have accepted the Code of Ethical Business Practice [1]. That Code determines the points of responsibility on the part of infobrokers. Responsibility concerns mainly care of the professional image through honesty, competence, observation of confidentiality, and respect of intellectual property rights. The infobroker's conduct consists in customer education, knowledge of law, and appreciation of the information value through the observation of all ethical principles. An information broker should be honest and competent, and offer current legal information. Special attention is paid to the observation of ethical principles referring to the customer in the context of making information available in an ethical manner.

\section{Conclusion}

Interest in the ethical aspects of information activities causes revision of the existing standards of professional conduct, and, consequently, it inspires us to create new codes of conduct. Our considerations indicate that, with respect to 
information, information ethics is equivalent to the need for the shaping of a particular human attitude towards information. That attitude means the readiness to learn the essence of information and message, and developing the skills of proper and responsible use of information.

\section{References}

[1] Association of Independent Information Professional. [on-line:] http://www. aiip.org/AboutAIIP/aiipethics.html.

[2] Babik W.: Sustainable Development of Information Society: Towards an Ecology of Information. Geomatics and Environmental Engineering (AGH-UST quarterly), vol. 2, no. 1, 2008, pp. 13-24.

[3] Babik W.: Infologic and Ecologic Aspects of Sustainable Development and the Society's Access to Information and Knowledge. Geomatics and Environmental Engineering (AGH-UST quarterly), vol. 3, no. 1, 2009, pp. 11-17.

[4] Capurro R.: Ethics and Information in the Digital Age. Contribution to LIDA 2001 Annual Course and Conference: Libraries in the Digital Age, Dubrovnik 23-27 May, 2001, [on-line:] http://www.capurro.de/lida.htm.

[5] Froehlich T.: A brief history of information ethics. Miscellaneous Papers in Computer and Information Science, vol. 13, 2004, [on-line:] http://www.ub. edu/bid/13froel2.htm.

[6] Kłoskowska A.: Kultura masowa. PWN, Warszawa 1983.

[7] Nowak E.P.: Broker informacji - odpowiedź na zapotrzebowanie XXI wieku. Zagadnienia Informacji Naukowej, nr 1(87), 2006, pp. 51-63.

[8] Zasępa: T. Media. Człowiek. Społeczeństwo. Doświadczenia europejsko-amerykańskie. Częstochowa 2000.

[9] http://www.itu.int/wsis/.

[10] http://www.info-ethics.com/information_ethics.html. 